\title{
0 Topo da Distribuição de Renda no Brasil: Primeiras Estimativas com Dados Tributários e Comparação com Pesquisas Domiciliares $(2006-2012)^{*}$
}

\author{
Marcelo Medeiros ${ }^{1}$ \\ Pedro H. G. Ferreira de Souza ${ }^{2}$ \\ Fábio Avila de Castro ${ }^{3}$ \\ ${ }^{1}$ Universidade de Brasília (UnB), Brasília, DF, Brasil. E-mail: mclmdr@unb.br. \\ ${ }^{2}$ Instituto de Pesquisa Econômica Aplicada (Ipea), Brasília, DF, Brasil. E-mail: \\ pedro.ferreira@ipea.gov.br. \\ ${ }^{3}$ Secretaria da Receita Federal, Brasília, DF, Brasil. E-mail: fabioavcastro@yahoo.com.br.
}

\section{INTRODUÇÃO}

T a maior parte dos países, há grande concentração de renda no 1 topo da distribuição, entre os mais ricos. Os levantamentos domiciliares, normalmente utilizados para analisar a distribuição de renda, no entanto, tendem a subestimar os rendimentos mais elevados, seja por limitações inerentes à amostragem e aos desenhos dos questionários, seja por omissão de respostas ou desconhecimento, por parte dos respondentes, dos valores exatos dos seus rendimentos. Uma alternativa para lidar com essa subestimação é analisar a desigualdade a partir de dados tributários.

Construímos uma série de indicadores de desigualdade com base nas declarações de Imposto de Renda da Pessoa Física. Tratamos aqui do $0,1 \%, 1 \%$ e $5 \%$ mais ricos, ou seja, estamos interessados sobretudo na desigualdade entre os mais ricos e o resto da população brasileira. Ricos, no caso, são entendidos como adultos de renda individual mais alta e não como aqueles que têm maior estoque de riqueza, embora seja

\footnotetext{
* Agradecemos pela colaboração de André Gambier Campos, Carlos Antonio Costa Ribeiro, Carlos Henrique Corseuil, Edmar Bacha, Emerson Rocha, Fernando Gaiger, José Alcides dos Santos, Lauro Stocco II, Leonardo Monastério, Luana Pinheiro, Luciana dos Santos Servo, Marcelo Caetano Abi-Ramia, Maria Lígia Barbosa, Rafael Guerreiro Osório, Rodolfo Hoffmann, Rodrigo Orair e Sergei Soares.
}

DADOS - Revista de Ciências Sociais, Rio de Janeiro, vol. 58, no 1, 2015, pp. 7 a 36. 
possível que haja coincidência entre ambos. A série cobre o período que vai de 2006 a 2012.

Além de apresentar os indicadores e avaliar sua sensibilidade a diferentes escolhas metodológicas, também comparamos os resultados obtidos a partir de dados tributários com os das principais pesquisas domiciliares brasileiras: a Pesquisa Nacional por Amostra de Domicílios (PNAD), a Pesquisa de Orçamentos Familiares (POF) e o Censo Demográfico, todas conduzidas pelo Instituto Brasileiro de Geografia e Estatística (IBGE). Esses levantamentos servem como fonte para a maioria dos estudos sobre a distribuição de renda no país e, portanto, a comparação pode ajudar a revelar a parte da desigualdade que não é bem conhecida por falta de dados apropriados.

Nossos principais achados são que a desigualdade no Brasil é superior à medida por pesquisas domiciliares e, apesar de um leve aumento, em termos gerais permanece estável no período 2006 a 2012. O maior nível de desigualdade está muito provavelmente relacionado à subestimação das rendas mais altas nas pesquisas domiciliares, em particular a PNAD. No que diz respeito à estabilidade não temos informações que nos permitam adiantar uma conclusão. As PNADs apontam uma queda da desigualdade de 2006 a 2012. Nossas evidências são de que os ricos são mais resistentes à queda da desigualdade do que o restante da população, mas não sabemos dizer a causa disso a partir dos dados limitados que dispomos. Aparentemente, os ricos podem ser qualitativamente diferentes, isto é, não são apenas uma "versão com mais renda" do que o restante da população, mas é evidente que isso não é mais do que uma hipótese a ser avaliada com mais cautela.

\section{ESTUDOS ANTERIORES}

O estudo da desigualdade a partir do topo da distribuição de renda e usando dados tributários tem uma longa história nas Ciências Sociais. O tema recebeu atenção de Marx (1996), Veblen (1988) e Pareto (1964), com Marx (1996:448, 479), em particular, utilizando informações tributárias para analisar a distribuição pessoal da renda tributável no Reino Unido entre 1864 e 1865. Existem análises mais detalhadas, com base em estatísticas tributárias e administrativas, desde pelo menos o início do século XX (Bowley, 1914; King, 1915; USA, Commission on Industrial Relations e Walsh, 1915). Não seria surpresa alguma encontrar referências ainda mais antigas sobre o assunto. 
O topo da distribuição pode ser abordado por vários ângulos, dentre eles a análise estatística de grandes populações. No Brasil esses estudos começam a surgir na década de 1930 e tornam-se mais comuns a partir da década de 1990 (Afonso, 2014; Albuquerque, 1994; Ferreira, 2001; Hoffmann, 2005; Medeiros, 2004, 2005a e 2005b; Souza, 2014). Recentemente o assunto começou a ganhar maior projeção com o trabalho de Piketty (2001) sobre altos rendimentos na França, que ocupou um espaço claro na agenda de pesquisa sobre desigualdade com um estudo similar para os Estados Unidos (Piketty e Saez, 2003), contribuindo para uma proliferação de estudos em vários países. Boa parte desses trabalhos refere-se a países ricos, mas a literatura sobre o tema no resto do mundo já começa a ganhar maiores dimensões.

O aumento no volume desses estudos resultou em artigos de revisão dedicados a analisar vários tópicos da literatura. Há resenhas sobre a relação entre o topo da distribuição e o nível e as tendências da desigualdade em diversos países que tratam o assunto com mais detalhe e profundidade do que somos capazes de fazer aqui (Alvaredo et al., 2013; Atkinson, 2008; Atkinson e Piketty, 2010; Atkinson, Piketty e Saez, 2011; Keister, 2014; Keister e Moller, 2000; Medeiros e Souza, 2014; Ohlsson, Roine e Waldenström, 2006; Piketty, 2007; Piketty e Saez, 2006; Torche e Spilerman, 2008; Wolff, 1996). Há também revisões de análises das lacunas preenchidas pela literatura baseada em informações tributárias, em particular a melhor estimativa de mudanças relacionadas aos rendimentos da população de renda alta, a possibilidade de se estenderem séries para períodos muito anteriores ao surgimento das pesquisas domiciliares e um monitoramento mais acurado de rendimentos que não são recebidos com a mesma regularidade que os rendimentos do trabalho (Atkinson, 2007; DiPrete, 2007; Kenworthy, 2007; Kopczuk, Saez e Song, 2010; Myles, 2003; Piketty, 2014). Essas revisões tornam, em parte, redundante nossa discussão de estudos antecedentes.

Em termos gerais, essas revisões mostram que os estudos baseados em informações tributárias de países europeus e da América do Norte encontram desigualdade elevada no início do século XX, seguida de uma queda que ocorre entre a Primeira e a Segunda guerra mundiais, um período de estabilidade que vai até início dos anos 1980 e um crescimento da desigualdade desde então. A duração de cada um desses períodos e as velocidades de mudança variam conforme o país. Nas décadas recentes o crescimento da desigualdade é notadamente mais

DADOS - Revista de Ciências Sociais, Rio de Janeiro, vol. 58, nº 1, 2015 
rápido nos países anglo-saxões que na Europa Continental, mas mesmo dentro desses grupos há heterogeneidade.

O que talvez mereça destaque é o uso de informação do imposto de renda para o estudo da desigualdade no Brasil. Neste sentido, nosso estudo dialoga com pesquisas recentes sobre a desigualdade de renda, em particular aquelas realizadas a partir dos anos 2000. Boa parte dessas pesquisas baseia-se em informações de levantamentos domiciliares como a PNAD, o Questionário da Amostra do Censo Demográfico (Censo) ou a POF. A maior parte da literatura especializada sobre o assunto avalia que pesquisas domiciliares, em particular a PNAD, subestimam as rendas no topo da distribuição e, portanto, fornecem uma visão parcial da desigualdade no país (Hoffmann, 1988; Hoffmann e Ney, 2008; Lluch, 1982; Souza, 2013). As informações do imposto de renda seriam uma maneira de contornar, ao menos parcialmente, o problema da subestimação das rendas no topo da distribuição.

\section{METODOLOGIA}

\section{Rendimentos nos Dados Tributários}

Definições principais dos dados tributários

Os dados tributários utilizados correspondem ao universo de declarações de ajuste anual do Imposto de Renda da Pessoa Física (DIRPF) à Receita Federal do Brasil (Receita) nos anos de 2006 a 2012. Embora existam declarantes no exterior, a grande maioria é residente no Brasil e, por isso, tratamos as declarações como se todas correspondessem à população brasileira residente. Nossa unidade tributária é o indivíduo, pois pressupomos que cada declaração equivale a uma pessoa. De acordo com a legislação tributária brasileira, casais e famílias podem entregar declarações de renda em conjunto, mas, em geral, isso não é vantajoso para quem tem rendimentos elevados.

Os declarantes de Imposto de Renda são o conjunto de pessoas físicas que receberam rendimentos acima de valores que variam para cada ano, obtiveram ganhos de capital acima de determinado valor, realizaram operações em bolsas de valores, ou tiveram a posse ou a propriedade de bens ou direitos acima dos valores estabelecidos pela legislação vigente. Nem toda a população com rendimentos, portanto, é obrigada à entrega da DIRPF. Aliás, há pessoas que recolhem tributos (tri- 
butação na fonte, por exemplo) e, no entanto, não têm o dever de apresentar declaração de ajuste anual do imposto de renda.

A renda bruta utilizada inclui todos os rendimentos declarados pelas pessoas físicas, isto é, a soma dos rendimentos tributáveis, isentos e sujeitos à tributação exclusiva. Isso inclui rendimentos do trabalho e capital recebidos por pessoas físicas, como, por exemplo, o recebimento de dividendos de aplicação financeira, ganhos de capital, lucros, aluguéis e rendimentos recebidos de outros países. Como há cruzamento de informações e tributação na fonte, há razões para crer que a maior parte dos rendimentos de aplicações financeiras e similares, que tendem a ser subdeclarados em levantamentos domiciliares, esteja muito mais bem representada nas declarações tributárias. Como não foi possível estimar o nível e a distribuição da elisão e da evasão fiscal, assumimos, para efeitos operacionais, que as declarações de renda refletem os rendimentos efetivamente recebidos.

Utilizamos dados provenientes do estudo de Castro (2014). O objetivo do autor era estimar os níveis de progressividade tributária no Brasil e seu achado principal é o de que o imposto de renda é fortemente progressivo. Nós, no entanto, aplicamos interpolações a seus dados de maneira a gerar distribuições de renda. Por questões de sigilo, não tivemos acesso aos microdados, mas, tão somente, aos resultados agregados em categorias ordenadas pela renda bruta total, de modo a evitar qualquer possibilidade de identificação individual. Essas categorias, porém, alcançam pontos altos da distribuição, como $1 \%$ no topo, o que é particularmente importante para o estudo da desigualdade entre os ricos e o resto da população. O Apêndice II contém as principais tabulações necessárias para replicar nosso estudo.

Declarações com valores extremos ou notadamente inconsistentes foram inspecionadas individualmente e eliminadas, quando havia indicações de que se tratava de erros de declaração. Essa depuração resultou na exclusão da base de, aproximadamente, 2.800 contribuintes no conjunto dos anos examinados, número pequeno perto das cerca de 25 milhões de declarações anuais observadas em média entre 2006 e 2012.

Há limitações nos dados tributários que merecem ser comentadas. A primeira refere-se à distribuição incompleta: apenas uma minoria dos brasileiros apresenta a Declaração Anual de Ajuste do Imposto de Renda e isso impede o cálculo direto de medidas como, por exemplo, o coeficiente de Gini. A segunda limitação refere-se à informação limitada:

DADOS - Revista de Ciências Sociais, Rio de Janeiro, vol. 58, nº 1, 2015 
não dispomos, no momento, de informações para calcular outras rendas, como a renda domiciliar per capita dos mais ricos, que são comumente usadas nos estudos sobre desigualdade no Brasil. A terceira é que as interpolações de Pareto que usamos tendem a subestimar a concentração da renda no topo extremo da distribuição. Finalmente, uma limitação adicional é a cobertura insuficiente: rendas que pertencem nominalmente a pessoas jurídicas, embora seja óbvio que sua propriedade seja, em última instância, de pessoas físicas (note-se, porém, que uma parte dos rendimentos de pessoas jurídicas transferidos às pessoas físicas está corretamente contabilizada em nossos dados). Assim, é possível que nossas estimativas da desigualdade estejam subestimadas, embora não tenhamos condições de fazer nenhum tipo de afirmação sobre a magnitude dessa subestimação. Discussões mais detalhadas sobre o assunto podem ser encontradas em Saez (2006), Atkinson (2007) e Atkinson et al. (2011).

\section{Denominador para a população total}

Utilizamos como denominador para a população total a população residente com 18 anos ou mais, de acordo com a revisão de 2013 das projeções oficiais do IBGE. Essa definição é semelhante à da literatura internacional, que em geral usa como população de base aquela entre 15 anos ou mais e 20 anos ou mais. Mudanças em um ou dois anos nas idades de corte não têm impacto relevante sobre a série de tempo, como se discute adiante.

Interpolação para obter frações exatas da população

Partindo de dados tabulados, foi necessário distribuir os rendimentos dentro das categorias de renda. Embora para esse fim existam várias metodologias possíveis (Brzezinski, 2014), optamos pela interpolação de Pareto, seguindo a metodologia mais comum na literatura internacional (Piketty, 2001:593-595, Anexo B). Uma análise detalhada das características das metodologias de estimativa de rendas no topo da distribuição encontra-se em Atkinson (2007). A fórmula da interpolação encontra-se no Apêndice I.

A interpolação de Pareto depende dos limites de renda das categorias e de dados observados sobre a população e os rendimentos totais nessas categorias. A partir dessas informações calculam-se os parâmetros da função de Pareto que permitem estimar a renda em pontos da distribuição para os quais não há observações desagregadas. 
Como os parâmetros da função de Pareto variam conforme a categoria de renda, seguimos o procedimento de Feenberg e Poterba (1993) de adotar o limite inferior da categoria de renda observada que fosse mais próximo do quantil da distribuição a estimar. A validação da metodologia de interpolação foi feita por comparação aos dados observados. Em 2010, por exemplo, nos dados tributários a renda observada no limite inferior do $0,99 \%$ da população de 18 anos ou mais era de cerca de $\mathrm{R} \$ 186,6$ mil, ao passo que nossa estimativa por interpolação calcula R\$ 179,1 mil, ou seja, o valor observado era apenas 2,5\% maior que o valor interpolado. Evidentemente, a qualidade da interpolação varia, tendendo a ser melhor no topo (entre os 5\% e o 1\%) da distribuição do que em sua base. É possível que nosso nível de desigualdade esteja subestimado, pois no topo extremo da distribuição a função de Pareto costuma ser insuficientemente inclinada para representar adequadamente os elevados níveis de concentração de renda (Brzezinski, 2014).

A Tabela 1 ilustra os resultados da interpolação para os anos de 2006 a 2012. Os valores são expressos em milhares de reais anuais, correntes do ano de referência. Em 2012, por exemplo, os limites inferiores de renda do $0,1 \%, 1 \%$ e $5 \%$ mais ricos são, respectivamente, $\mathrm{R} \$ 871,7$ mil, $\mathrm{R} \$ 203,1$ mil e $\mathrm{R} \$ 57,6$ mil ao ano. A renda média do 1\% mais rico, obtida por interpolação, foi de R $\$ 552,9$ mil anuais. Nos dados observados

Tabela 1

Renda Mínima e Renda Média dos 0,1\%, 1\%, 5\% mais Ricos e Renda Média Total

(R\$ milhares correntes, anuais)

(Brasil, 2006-2012)

\begin{tabular}{l|r|r|r|r|r|r|r}
\hline & $\mathbf{2 0 0 6}$ & $\mathbf{2 0 0 7}$ & $\mathbf{2 0 0 8}$ & $\mathbf{2 0 0 9}$ & $\mathbf{2 0 1 0}$ & $\mathbf{2 0 1 1}$ & $\mathbf{2 0 1 2}$ \\
\hline $\mathbf{0 , 1 \%}$ mais rico \\
\hline Mínima & 452,7 & 508,9 & 630,9 & 645,3 & 732,5 & 843,2 & 871,7 \\
Média & $1.185,0$ & $1.458,6$ & $1.804,1$ & $1.736,9$ & $1.960,5$ & $2.402,6$ & $2.373,5$ \\
\hline
\end{tabular}

$1 \%$ mais rico

\begin{tabular}{l|r|r|r|r|r|r|r}
\hline Mínima & 109,1 & 113,6 & 141,2 & 151,8 & 168,7 & 189,2 & 203,1 \\
Média & 285,6 & 325,7 & 403,6 & 408,6 & 464,5 & 539,1 & 552,9 \\
\hline
\end{tabular}

$5 \%$ mais ricos

\begin{tabular}{l|r|r|r|r|r|r|r}
\hline Mínima & 30,5 & 31,5 & 38,6 & 41,9 & 46,7 & 52,1 & 57,6 \\
Média & 103,5 & 111,8 & 140,3 & 146,2 & 164,6 & 188,3 & 197,7 \\
\hline Média: Brasil & $\mathbf{1 2 , 2}$ & $\mathbf{1 3 , 5}$ & $\mathbf{1 5 , 1}$ & $\mathbf{1 5 , 8}$ & $\mathbf{1 8 , 1}$ & $\mathbf{1 9 , 6}$ & $\mathbf{2 0 , 4}$ \\
\hline
\end{tabular}

Fonte: Renda dos estratos - interpolação a partir dos dados da DIRPF 2006 a 2012; População - IBGE, projeções de população; Renda das famílias - estimada a partir das Contas Nacionais do IBGE. 
de 2012 , apenas $1,6 \%$ da população adulta, ou seja, pouco menos de 2,3 milhões de brasileiros, declarou receber renda anual acima de $\mathrm{R} \$ 149.280$. A renda média efetivamente observada nesse grupo foi de $\mathrm{R} \$ 406,5$ mil anuais.

\section{Denominador para a renda total}

Com a população total e a interpolação de Pareto, obtivemos a renda total dos centésimos e milésimos mais ricos da população. Para transformar esses valores em frações da renda, precisamos calcular o denominador, isto é, a renda total, que foi obtida a partir das Contas Nacionais, como preconiza a literatura internacional. Mais especificamente, usamos os dados públicos das séries trimestrais das Contas Nacionais, elaboradas pelo IBGE para construir a renda total usando a definição mais compatível com a renda nos dados tributários.

A melhor forma de construir o denominador da renda requer os dados detalhados das Contas Nacionais anuais. A renda total compatível com a definição de renda dos dados tributários é obtida pelo cálculo, para o setor institucional "famílias", dos ordenados e salários mais o excedente operacional bruto mais o rendimento misto bruto (rendimento de autônomos) mais os juros mais dividendos e retiradas mais os benefícios sociais (exceto transferências sociais em espécie) mais as outras transferências correntes, menos os aluguéis imputados. Os valores dos rendimentos foram obtidos nas Contas Econômicas Integradas (CEI), e os aluguéis imputados estão nas Tabelas de Recursos e Usos (TRU).

Infelizmente, os números necessários para o cálculo desse denominador ideal para a renda (doravante chamado de Renda Monetária Familiar - RMF) só estão disponíveis na publicação detalhada das Contas Nacionais anuais, que, devido à sua complexidade, só são divulgadas com defasagem de alguns anos. Como nossa série vai até 2012, optamos por um procedimento alternativo, com base nas Contas Nacionais trimestrais, para todo o período de 2006 a 2012.

Assim, observamos que a razão entre a renda monetária familiar (o denominador da renda definido acima) e o Produto Interno Bruto (PIB) para o período de 2006 a 2009 equivale, aproximadamente, a 66,7\% ou seja, dois terços - do valor do PIB. Utilizamos esse valor para definir o denominador de renda monetária em nosso estudo. Este valor é próximo ao valor médio observado por Vélez (2012) para a Colômbia entre 
1993 e 2010 (65\%). Mais adiante, avaliamos o impacto da escolha de diferentes denominadores sobre a fração da renda apropriada pelo $1 \%$ mais rico.

\section{Rendimentos nos levantamentos amostrais}

As informações utilizadas para comparação com levantamentos domiciliares foram obtidas dos microdados das PNADs de 2006 a 2012, da POF 2008/2009 e da amostra do Censo 2010. Em todos os casos, consideramos a renda bruta total dos adultos com 18 anos ou mais. Indivíduos com rendimentos ignorados ou não declarados em alguma fonte foram descartados. Diferentemente do que ocorreu com os dados tributários, obtivemos o total da população e da renda nas informações contidas nos próprios levantamentos.

Os três levantamentos diferem principalmente quanto à regularidade, ao tamanho de suas amostras, ao detalhamento dos questionários e à duração dos períodos de referência para coleta dos rendimentos. Os censos são decenais, as POFs ocorrem em períodos irregulares e superiores a cinco anos, e as PNADs são anuais (exceto em anos censitários). A amostra do Censo 2010 contém 14,3 milhões de registros de adultos de 18 anos ou mais, enquanto as PNADs de 2006 a 2012 contam, em média, com pouco mais de 260 mil adultos, e a POF 2008 / 2009 com pouco menos de 130 mil. No entanto, o questionário mais completo e com maior período de referência é justamente o da POF, que coleta os rendimentos recebidos de dezenas de fontes nos 12 meses anteriores à entrevista. Nas PNADs e no Censo, os rendimentos estão relacionados a um mês de referência, sendo que este último apresenta o menor grau de detalhamento.

Para possibilitar a comparabilidade das PNADs e do Censo com os dados tributários, anualizamos as rendas nas pesquisas domiciliares. Essa anualização consistiu em multiplicar por 12 todos os rendimentos e acrescentar o equivalente ao 13 o salário para trabalhadores formais e aposentados, além de um terço de salário como bônus de férias aos trabalhadores formais. No Censo, não é possível identificar exatamente as aposentadorias e pensões previdenciárias quando há duas ou mais fontes de rendimento além dos rendimentos do trabalho. Nesse caso, assumimos que as aposentadorias representavam $80 \%$ do total de outros rendimentos para pessoas cuja renda de outros rendimentos era menor ou igual a $\mathrm{R} \$ 10.000$ e $50 \%$ caso a renda de outros rendimentos

DADOS - Revista de Ciências Sociais, Rio de Janeiro, vol. 58, nº 1, 2015 
fosse superior a esse valor. Ou seja, multiplicamos os "outros rendimentos" por 12,8 e 12,5, respectivamente. Na prática, a anualização eleva os níveis totais de rendimento, mas provoca pouca alteração na desigualdade: a mudança no coeficiente de Gini das rendas individuais de adultos é inferior a $2 \%$.

Os três levantamentos captam a renda total dos indivíduos, mas os resultados variam em função das características de cada um, como é discutido por Souza (2013). As vantagens de uma amostra maior são, em parte, reduzidas por questionários menos detalhados e períodos de cobertura mais curtos. Em termos gerais, os rendimentos totais mais altos são captados pelo Censo 2010, seguido da POF e, em terceiro lugar, das PNADs. Em tese, esses rendimentos equivalem a rendas brutas. No entanto, é provável que para muitas pessoas a renda efetivamente declarada corresponda à renda líquida, ou mesmo ao valor líquido percebido (Rocha, 2002). Não se deve esperar, portanto, comparabilidade perfeita entre os dados tributários e as pesquisas domiciliares, mesmo com a anualização das rendas.

Há evidências de que, em outros países, dados tributários e levantamentos domiciliares amostrais diferem mais no nível que no comportamento da desigualdade, embora haja exceções. Estudos anteriores mostram que resultados obtidos a partir de dados tributários e levantamentos domiciliares geralmente apresentam divergências no topo da distribuição, mas mostram-se comparáveis para níveis mais baixos (Burkhauser et al., 2012; Kopczuk e Saez, 2004; Leigh, 2007). Os níveis medidos de desigualdade com cada fonte de dados tendem a ser distintos, mas sua evolução costuma apontar as mesmas tendências, com uma forte correlação entre o coeficiente de Gini e a razão entre a renda dos ricos e a renda total em 13 países estudados por Atkinson et al. (2011).

\section{Aumento nas Quantidades de Declarações e Valores Declarados}

Entre 2006 e 2012 há um aumento na soma das rendas declaradas na DIRPF (52\%). Chama a atenção porque é um crescimento superior ao observado da renda nas Contas Nacionais e nas PNADs. Usando os mesmos deflatores (Índice Nacional de Preços ao Consumidor - INPC, de setembro), para evitar desvios causados pelo índice de preços, nesse mesmo período a renda das famílias (dois terços do PIB) cresce $33 \%$ e a renda total na PNAD cresce $34 \%$. 
O que efetivamente pode afetar nossos resultados não são as variações nos totais da DIRPF, mas tão somente aquelas variações no topo da distribuição, visto que descartamos completamente os dados na base da DIRPF. Ainda assim o assunto merece maior consideração. O aumento do número e do valor total das declarações pode decorrer de quatro fatores básicos: i) crescimento da renda ou do número de pessoas que antes estavam abaixo dos níveis de obrigatoriedade de declaração; ii) mudanças nos valores mínimos de obrigatoriedade de declaração; iii) aumento do número de declarações no topo da distribuição causado por algum tipo de enrijecimento na fiscalização tributária; iv) erros de registro.

De fato, como é bem conhecido, ocorreu inequivocamente um crescimento da renda total (34\% de 2006 a 2012 na renda monetária das famílias nas Contas Nacionais) e do número da população brasileira abaixo dos níveis de declaração (no caso, entre pessoas que estavam entre os percentis $75 \%$ e $85 \%$ da distribuição) e apenas isso seria suficiente para aumentar o número de declarantes e a renda declarada. Não é possível calcular quanto, no entanto, pois isso depende de uma distribuição completa de rendimentos e os rendimentos tributários limitam-se ao topo declarado da distribuição.

Também ocorreu crescimento e envelhecimento populacional que, apesar do pequeno intervalo de tempo, aumenta o número de adultos (11\% de 2006 a 2012). Os valores mínimos de obrigatoriedade foram aumentados em $18 \%$, o que é muito menos que o necessário para acompanhar o crescimento da renda das famílias e também faz o número de declarantes aumentar. Não há evidência de nenhuma mudança sistemática associada ao enrijecimento na fiscalização tributária que justificasse, por exemplo, crescimento de 2005 em diante. Na verdade isso é pouco provável, pois na DIRPF os rendimentos tributáveis têm crescido menos do que os outros, o oposto do esperado de um enrijecimento da fiscalização. Finalmente, erros de registro, evidentemente, são sempre uma possibilidade, mas para afetar nossas estimativas eles deveriam ser crescentes e sistemáticos e é pouco provável que isto esteja ocorrendo.

Por um lado, não é possível afastar completamente a hipótese de que uma parte do crescimento da renda captada pela DIRPF pode estar associada a algum tipo de viés ou erro que não fomos capazes de identificar. Por outro, não há evidência concreta desse viés. Para estar

DADOS - Revista de Ciências Sociais, Rio de Janeiro, vol. 58, nº 1, 2015 
ocorrendo ele precisaria se manifestar não só entre os 5\% e o 1\% mais ricos mas, também, acima do $1 \%$ e do $0,1 \%$ mais ricos. Se ele existe, possivelmente está afetando o comportamento da desigualdade no tempo. O mais provável é que se há algum erro afetando a mensuração é que ele seja na direção de elevar a desigualdade. Por exemplo, o aumento da desigualdade observado em 2008 e, novamente, em 2011, pode não ter ocorrido. Neste caso, a interpretação mais prudente é de estabilidade da desigualdade em todo o período. Menos provável, mas ainda assim possível, é que a desigualdade tenha caído levemente.

\section{O NÍVEL E A EVOLUÇÃO DA DESIGUALDADE NOS DADOS DA DIRPF}

\section{Percentuais Apropriados pelos Mais Ricos}

Os mais ricos apropriam-se de uma parcela substantiva da renda total, sem mudanças claras entre 2006 e 2012. O Gráfico 1 traz os percentuais apropriados pelos $0,1 \%, 1 \%$ e $5 \%$ mais ricos, de acordo com os dados da DIRPF. Nesse período, em média, o $0,1 \%$ mais rico recebeu quase $11 \%$ da renda total, o que implica que sua renda média foi quase 110 vezes maior do que a média nacional. O 1\% mais rico, incluindo esse $0,1 \%$, apropriou-se de $25 \%$, e os $5 \%$ mais ricos receberam $44 \%$, quase a metade da renda total. Na Colômbia e nos Estados Unidos a parcela do 1\%

\section{Gráfico 1}

Percentual da Renda Total Apropriado pelo 0,1\%, pelo 1\% e pelos 5\% Mais Ricos

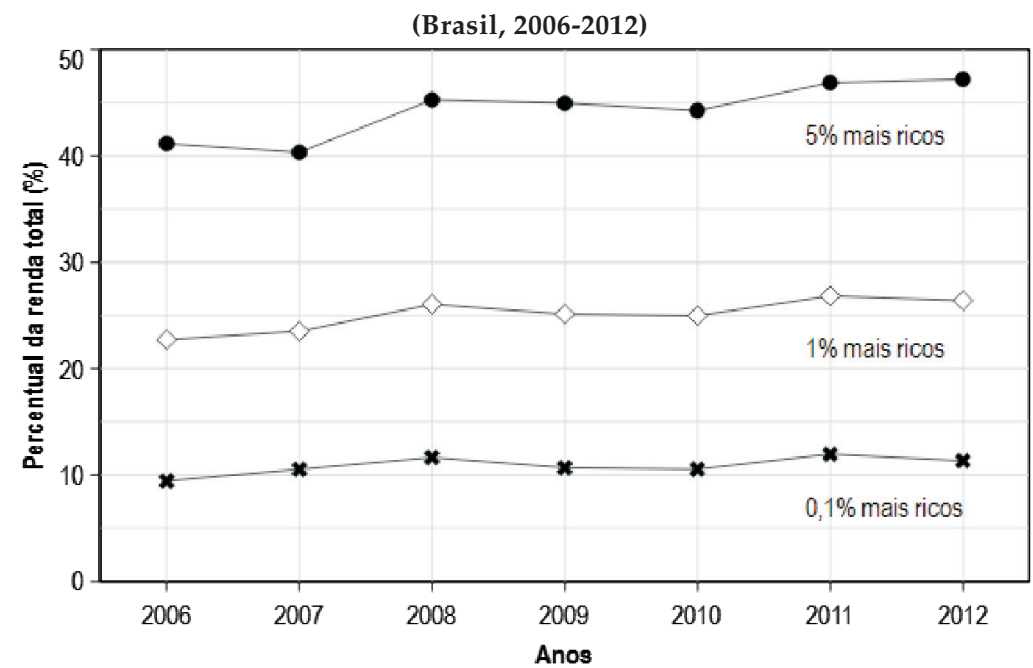

Fonte: Renda dos estratos - DIRPF 2006 a 2012; População - IBGE, projeções de população; Renda das famílias - estimada a partir das Contas Nacionais do IBGE. 
mais rico na renda total situa-se em torno de 20\% (Piketty e Saez, 2013; Vélez, 2012). Os resultados para outros países desenvolvidos indicam percentuais entre $10 \%$ e $15 \%$, caindo abaixo disso nos países mais igualitários (Atkinson, Piketty e Saez, 2011). Todavia, diferenças entre países e sistemas tributários impedem que esses números sejam diretamente comparados aos nossos.

Há um pequeno aumento da concentração entre o $1 \%$ mais rico no período entre 2006 e 2008, mas o quadro geral é de estabilidade. Vale lembrar que as medidas de desigualdade exibidas no Gráfico 1 só consideram uma pequena parte da distribuição da renda, ignorando, por exemplo, tudo o que acontece entre os $95 \%$ mais pobres. Esse possível aumento da desigualdade precisa ainda ser avaliado levando em conta a distribuição completa dos rendimentos. Porém, é provável que a queda da desigualdade nesse período, identificada nas pesquisas domiciliares, não tenha ocorrido ou tenha sido muito inferior ao que é comumente medido. As pesquisas domiciliares, tudo indica, identificam melhoras na base da distribuição, mas a desigualdade total depende também do que ocorre no topo.

\section{Análises de Sensibilidade para o Cálculo das Frações da Renda Apropriadas pelos Mais Ricos}

\section{Diferentes denominadores de renda}

O denominador para a renda total pode influenciar enormemente os resultados. Como discutimos anteriormente, usamos $66,7 \%$ do PIB (dois terços) em função da indisponibilidade de informações necessárias para calcular os valores de forma mais precisa. Nesta seção, comparamos nossos resultados com os decorrentes de outras escolhas.

O Gráfico 2 traz os percentuais da renda total apropriados pelo 1\% mais rico entre 2006 e 2012 para quatro denominadores diferentes. Para tornar as diferenças mais perceptíveis, alteramos a escala do eixo vertical em relação ao Gráfico 1.

A série "RMF" usa como denominador a renda monetária familiar, o denominador mais adequado para a renda, obtido a partir da aplicação da fórmula apresentada anteriormente aos dados das CEI. Portanto, essa série só é calculável para o período de 2006 a 2009. A série “66,7\% do PIB" é a nossa definição para todo o período, ou seja, é a

DADOS - Revista de Ciências Sociais, Rio de Janeiro, vol. 58, nº 1, 2015 
Gráfico 2

Percentual da Renda Apropriada pelo 1\% Mais Rico com Diferentes Definições de Renda Total

(Brasil, 2006-2012)

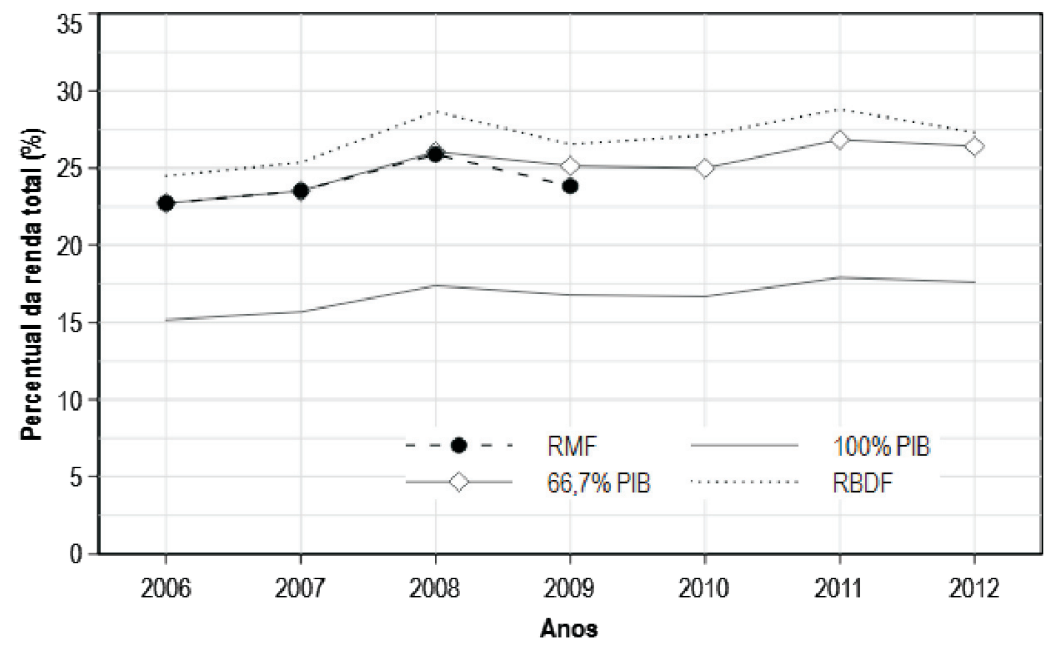

Fonte: Renda dos estratos - DIRPF 2006 a 2012; População - IBGE, projeções de população; Renda das famílias - estimada a partir das Contas Nacionais do IBGE.

mesma série do Gráfico 1. A série "100\% do PIB" adota como denominador para a renda total todo o PIB.

Por fim, a série "RBDF" utiliza como referência a renda bruta disponível das famílias, que corresponde à soma da despesa final de consumo e da poupança bruta das famílias. A definição de RBDF aproxima-se daquela utilizada por Piketty e Saez (2003) no estudo dos EUA. Para o período 2006 a 2009, a RBDF foi obtida diretamente na CEI (renda disponível bruta do setor institucional "famílias"). Para os anos de 2010 a 2012, utilizamos valores correspondentes a 103\% da despesa de consumo das famílias e instituições sem fins lucrativos (DCFI) nas Contas Nacionais Trimestrais. Esse multiplicador corresponde à razão média observada entre a RBDF e a DCFI para os anos de 2006 a 2009. Vale observar que, entre outros motivos, a RDBF difere com relação ao denominador ideal porque inclui rendimentos não monetários, como os aluguéis imputados às famílias que moram em imóveis próprios, bem como as contribuições sociais pagas pelos empregadores.

Nenhum dos quatro denominadores altera a tendência geral de estabilidade da desigualdade acompanhada de um leve aumento entre 2006 e 2008. As diferenças entre o denominador ideal (RMF) e o denomina- 
dor de dois terços do PIB são muito modestas, e seus valores médios entre 2006 e 2009 são praticamente idênticos. A série com a renda disponível bruta das famílias (RBDF) também gera resultados muito parecidos quanto ao nível e à tendência da desigualdade.

Por definição, a série com 100\% do PIB altera apenas o nível de concentração de renda no topo: em média, a fração de renda do $1 \%$ mais rico cai de $25 \%$ para $17 \%$. Como essa escolha é extrema, pode-se interpretá-la como um piso para a desigualdade. Trata-se de um piso pouco realista, pois o PIB é um conceito muito mais amplo do que a renda monetária das famílias, mas, como veremos adiante, mesmo esse valor mínimo é superior ao observado na maior parte dos levantamentos domiciliares. Em resumo, a concentração de renda no topo é impressionante. Não importa como a medida seja construída, a desigualdade que ela expressa é extremamente alta e não dá sinais claros de mudança.

\section{Diferentes denominadores de população}

Não existe limite etário para a obrigatoriedade da apresentação da DIRPF, mas, por razões óbvias, a quantidade de declarantes em idades inferiores a 18 anos é baixa. Em 2012 essas declarações representavam bem menos que $1 \%$ de todas as declarações e seu rendimento tributável total era de pouca relevância. Nossos cálculos foram realizados levando-se em conta a população de base de 18 anos de idade ou mais projetada pelo IBGE. Seria possível, no entanto, selecionar outro recorte etário, o que poderia alterar a parcela de renda apropriada pelo $1 \%$ mais rico e demais estratos.

Para avaliar a sensibilidade dos resultados a variações nos grupos etários de referência, refizemos os cálculos utilizando cinco séries diferentes, movendo a idade mínima para zero, 15, 18, 20 e 25 anos. A trajetória da concentração de renda entre o $1 \%$ mais rico é idêntica nas cinco séries. O nível de concentração é mais variável: quanto mais alto o corte etário, menor a fração da renda total apropriada pelo 1\% mais rico. É fácil entender o motivo: mudanças no total da população afetam o número de pessoas no centésimo mais rico e, portanto, o total de renda desse estrato. Cortes etários mais altos geram grupos menores e, consequentemente, menos renda total, que é, então, dividida por um denominador fixo. 
Mudanças menores, como a redução da idade mínima para 15 anos, ou seu aumento para 20, alteram muito pouco o nível da concentração de renda no topo. Na definição que julgamos mais adequada, população com 18 anos ou mais, o 1\% mais rico se apropria, na média do período, de pouco menos de $25 \%$ da renda total. Grosso modo, se usarmos a população com idade mínima de 15 ou 20 anos, esse número sobe ou desce apenas cerca de 0,5 ponto percentual. Em termos substantivos, a mudança de corte para pontos próximos a 18 anos não provoca alterações na interpretação dos resultados que mereçam atenção.

As escolhas mais extremas provocam mudanças mais perceptíveis visualmente, mas ainda pouco relevantes na prática. Na opção mais extrema, sem recorte algum de idade, o $1 \%$ mais rico da população acumularia, na média entre 2006 e 2012, quase 29\% da renda. Restringindo-se a população aos indivíduos com 25 anos ou mais, essa média cai para $23 \%$.

Em suma, os resultados quanto à trajetória são robustos a diferentes denominadores de renda e população. No que diz respeito ao nível da concentração de renda no topo, apenas as escolhas mais extremas como usar toda a população ou todo o PIB como denominadores - provocam variações dignas de nota, sendo que os efeitos de cada escolha atuam em direções inversas: usar toda a população aumenta a fatia do $1 \%$ mais rico, enquanto usar todo o PIB provoca sua redução.

\section{A Desigualdade entre os mais ricos}

Para terminar a análise dos dados tributários, cabe apresentar a desigualdade entre os mais ricos, isto é, a concentração medida pelas razões entre as rendas dos estratos mais altos. Uma vantagem desse tipo de abordagem é que os resultados independem da definição de renda total e são muito pouco sensíveis ao recorte populacional utilizado.

O Gráfico 3 apresenta três séries: a razão entre a renda total do 0,1\% mais rico e a do $1 \%$ mais rico; a razão entre o $0,1 \%$ e os $5 \%$ mais ricos; e a razão entre o $1 \%$ mais rico e os $5 \%$ mais ricos. Mais uma vez, há relativa estabilidade ou flutuação cíclica no período analisado, de modo que as diferenças nos níveis chamam mais a atenção: há muita desigualdade mesmo entre os mais ricos, com enorme concentração justamente entre os mais ricos dentre os mais ricos. 
Gráfico 3

Razões entre as Rendas Totais dos Estratos

(Brasil, 2006-2012)

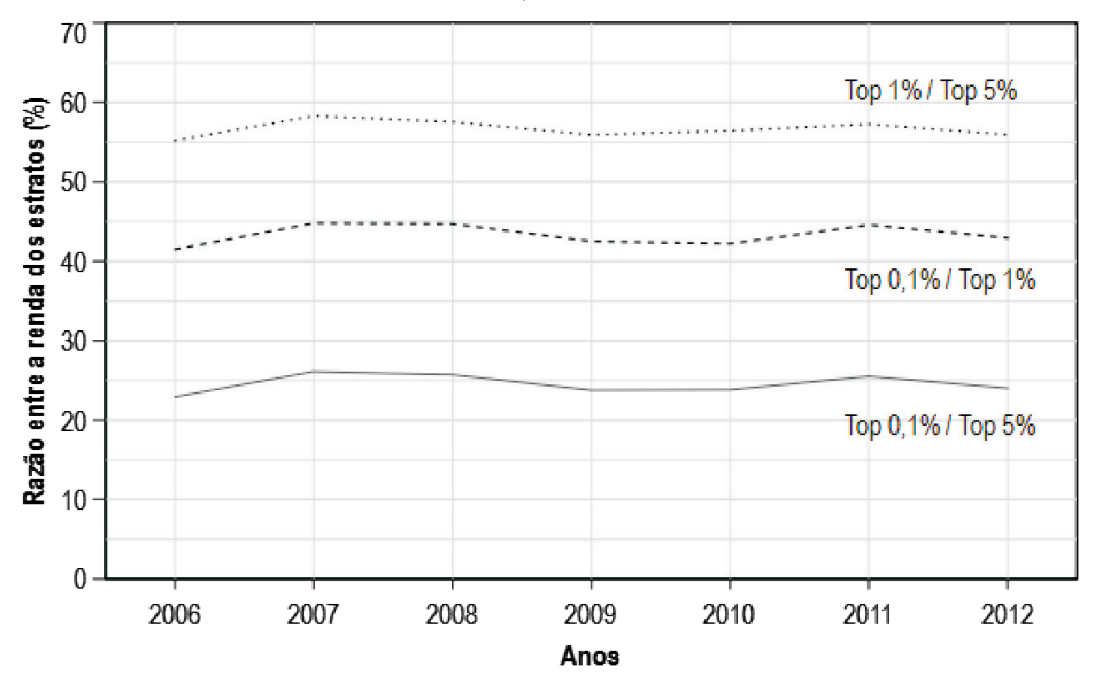

Fonte: Renda - DIRPF 2006 a 2012; População - IBGE, projeções de população.

Em média, entre 2006 e 2012, o 0,1\% mais rico apropriou-se de $43 \%$ da renda total do $1 \%$ mais rico e de quase $25 \%$ da renda total dos $5 \%$ mais ricos. Isso significa que, em 2012, os cerca de 140 mil brasileiros pertencentes ao milésimo mais rico da distribuição tiveram renda média quase sete vezes maior do que a do o resto dos indivíduos no centésimo mais rico e quase 22 vezes maior do que a dos indivíduos entre os percentis 95 e 99 (os 5\% mais ricos, excluindo o centésimo mais rico), além de 116 vezes maior do que a média nacional.

Comparação com resultados de pesquisas domiciliares amostrais

Os trabalhos de Lluch (1982), Hoffmann $(1988,2001)$ e Souza (2013) indicam que as pesquisas domiciliares brasileiras subestimam a desigualdade no país, em boa medida devido à má captação dos rendimentos nos estratos mais ricos da população. Há, no entanto, ao menos um estudo com opinião diversa, a de que a subestimação da renda nas pesquisas domiciliares não tem importância para a desigualdade (Barros, Cury e Ulyssea, 2006). Para avaliar a hipótese de que a subestimação é relevante para a desigualdade, comparamos os resultados obtidos com dados tributários aos de pesquisas domiciliares utilizando distribuições equivalentes: renda individual de todas as fontes das pessoas com

DADOS - Revista de Ciências Sociais, Rio de Janeiro, vol. 58, nº 1, 2015 
idade igual ou superior a 18 anos. O Gráfico 4 mostra a fração da renda total apropriada pelo $1 \%$ mais rico nos dados tributários, nas PNADs de 2006 a 2012, no Censo 2010 e na POF 2008-2009. Realizamos cálculos semelhantes para o $0,1 \%$ e os $5 \%$, mas não apresentamos os resultados no gráfico.

\section{Gráfico 4}

Fração da Renda Total Apropriada pelo 1\% Mais Rico nos Dados Tributários e nas Pesquisas Domiciliares

(Brasil, 2006-2012)

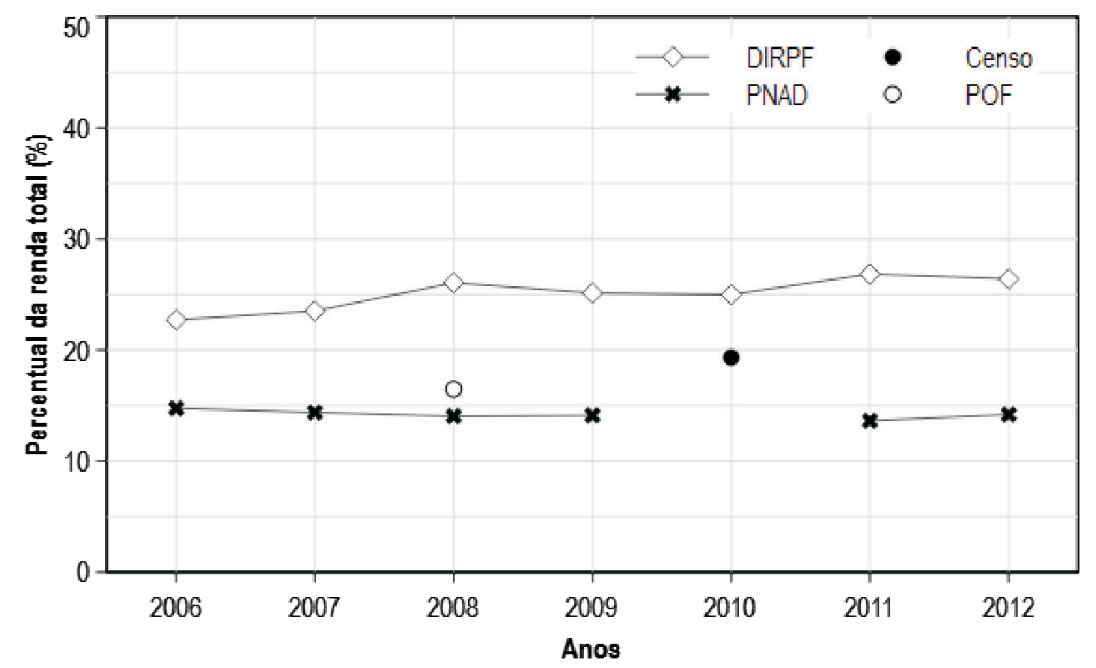

Fonte: Renda da classe - DIRPF 2006 a 2012; População - IBGE, projeções de população; Renda das famílias - estimada a partir das Contas Nacionais do IBGE; PNADs 2006 a 2012; Censo Demográfico 2010; POF 2008/2009.

Há três aspectos que se destacam. Em primeiro lugar, os levantamentos domiciliares mostram menor nível de concentração no topo do que os dados tributários. As PNADs apresentam as estimativas mais baixas, seguidas de perto pela POF. Nesses dois levantamentos, a fração $0,1 \%$ mais rico varia em média em torno de $3 \%$ ou $4 \%$ da renda (não mostrada no gráfico), a do $1 \%$ mais rico fica entre $14 \%$ e $16 \%$ e a dos $5 \%$ mais ricos tem média próxima a 35\%. No Censo 2010, esses valores são bem mais altos - respectivamente, $7 \%, 19 \%$ e $40 \%$-, o que muito provavelmente está relacionado ao maior tamanho da amostra. Os resultados com base nos dados tributários são ainda mais elevados, com médias arredondadas de $11 \%, 25 \%$ e $44 \%$ para o $0,1 \%$, o $1 \%$ e os $5 \%$ mais ricos. Mesmo no caso mais extremo, em que todo o PIB é usado como 
denominador da renda, a fração do 1\% mais rico nos dados tributários permanece superior à registrada nas PNADs e nas POFs, e apenas pouco abaixo daquela do Censo.

Em segundo lugar, os números também revelam que a discrepância é maior em pontos mais altos da distribuição. Comparando as médias nos períodos, a fração do $0,1 \%$ mais rico é mais de 7 pontos percentuais mais alta nos dados tributários do que nas PNADs, enquanto a fração do resto do centésimo mais rico - isto é, dos indivíduos entre os quantis 99 e 99,9 - é menos de 4 pontos percentuais mais alta, e a fração do grupo entre os quantis 95 e 99 - os 5\% mais ricos excluindo o centésimo superior - é bem parecida com a das PNADs e até um pouco menor. A diferença na POF é semelhante, mas o Censo 2010 é mais próximo dos números da DIRPF em função da melhor captação da renda dos mais ricos entre os mais ricos: a fração do $0,1 \%$ mais rico é pouco menos de 4 pontos percentuais maior na DIRPF para o ano-calendário de 2010 do que no Censo. A fração do resto do centésimo mais rico é 2 pontos percentuais maior e a fração dos $5 \%$ mais ricos excluindo o $1 \%$ mais rico é 2 pontos percentuais menor.

Em terceiro, também pode-se ver que a tendência de queda na desigualdade geral que se observa no Brasil não encontra correspondência no topo da distribuição, nem mesmo nos levantamentos domiciliares. Entre 2006 e 2012, para o 0,1\% e o 1\% mais rico, há leve aumento nos dados tributários e estabilidade nas PNADs. Mesmo quando consideramos os $5 \%$ mais ricos, a tendência na PNAD é de queda suave, de $36 \%$ em 2006 para 33\% em 2012. Como a fração do 1\% mais rico variou muito pouco, quase toda essa queda na PNAD é decorrente da diminuição da fatia dos indivíduos entre os percentis 95 e 99.

Colocando de modo simplificado, os levantamentos domiciliares amostrais também indicam que os ricos são mais resistentes à queda da desigualdade que o restante da população. Essa estabilidade no extremo superior também é identificada quando se observam outras distribuições, como a dos rendimentos domiciliares per capita de toda a população. Se essa elite se mantém estável no tempo, a maior parte da mudança na desigualdade deve ocorrer entre os estratos que estão mais na base e no centro da distribuição.

Por fim, a Tabela 2 traz os cálculos das "parcelas sobre parcelas", isto é, as razões entre as rendas dos estratos, o que nos permite avaliar como cada fonte de dados capta a desigualdade entre os mais ricos. Esses nú-

DADOS - Revista de Ciências Sociais, Rio de Janeiro, vol. 58, nº 1, 2015 
meros são independentes do denominador de renda. Em comparação com os dados tributários e mesmo com o Censo, as PNADs e as POFs subestimam a desigualdade entre os mais ricos. Vemos, por exemplo, que nos dados do Imposto de Renda, em média, mais de 56\% da renda total do vigésimo mais rico vai para o centésimo mais rico e quase um quarto vai para o milésimo mais rico. Nas PNADs, em média, pouco menos de $42 \%$ da renda dos $5 \%$ mais ricos vai para quem está no $1 \%$ e apenas um décimo vai para o $0,1 \%$ mais rico.

Tabela 2

Razões entre as Rendas Totais dos Estratos nos Dados Tributários e nas Pesquisas Domiciliares (Brasil, 2006-2012)

(\%)

\begin{tabular}{l|c|c|c}
\hline & $\mathbf{0 , 1} \%$ / 1\% Mais Rico & $\mathbf{0 , 1} \%$ / 5\% Mais Ricos & $\mathbf{1 \% ~ / ~ 5 \% ~ M a i s ~ R i c o s ~}$ \\
\hline DIRPF* & 43,3 & 24,6 & 56,7 \\
PNAD* & 24,2 & 10,1 & 41,6 \\
Censo 2010 & 34,6 & 16,6 & 48,0 \\
POF 2008/2009 & 23,5 & 10,0 & 42,5 \\
\hline
\end{tabular}

Fonte: Renda dos estratos - DIRPF 2006 a 2009; População - IBGE, projeções de população; Renda das famílias - estimada a partir das Contas Nacionais do IBGE; PNAD 2006 a 2012; Censo Demográfico 2010; POF 2008/ 2009.

* Médias do período 2006-2012.

Em consequência de tudo isso, as linhas de cortes para pertencer aos estratos mais ricos são muito mais altas na DIRPF do que nas pesquisas domiciliares, principalmente a partir do percentil 99, como se vê na Tabela 3. Em 2012, a renda mínima para pertencer ao 1\% e aos 5\% mais ricos nos dados tributários era de $\mathrm{R} \$ 203$ mil e $\mathrm{R} \$ 58$ mil anuais, respectivamente. Na PNAD 2012 com valores anualizados (como descritos acima), os mesmos cortes eram de $\mathrm{R} \$ 120$ mil e $\mathrm{R} \$ 48$ mil. Ou seja, as linhas de corte do $1 \%$ e dos $5 \%$ nos dados tributários eram, respectivamente, $70 \%$ e $20 \%$ maiores do que na PNAD 2012. O mesmo padrão se repete para as rendas médias: em 2012, a média nacional com os denominadores escolhidos (66,7\% do PIB e população de 18 anos ou mais) era de R \$20,9 mil, valor 38\% maior do que na PNAD 2012. Já a renda média dos $5 \%$ mais ricos nos dados tributários girava em torno de R\$ 200 mil, quase o dobro da PNAD, e a do 1\% mais rico era superior a R \$ 550 mil, ou 2,6 vezes o valor da PNAD. Em todos os casos, os valores observados para o percentil 95 nos levantamentos domiciliares são muito mais próximos aos dos dados tributários do que os do percentil 99. 
Tabela 3

Renda Mínima e Renda Média dos 0,1\%, 1\%, 5\% Mais Ricos e Renda Média Total (R\$ correntes) na DIRF e nos Levantamentos Domiciliares

\begin{tabular}{|c|c|c|c|c|c|c|}
\hline & $\begin{array}{c}\text { DIRPF } \\
2008 \\
\end{array}$ & $\begin{array}{c}\text { POF } \\
2008 / 2009\end{array}$ & $\begin{array}{c}\text { DIRPF } \\
2010 \\
\end{array}$ & $\begin{array}{c}\text { Censo } \\
2010 \\
\end{array}$ & $\begin{array}{c}\text { DIRPF } \\
2012 \\
\end{array}$ & $\begin{array}{c}\text { PNAD } \\
2012 \\
\end{array}$ \\
\hline \multicolumn{7}{|l|}{$0,1 \%$ mais rico } \\
\hline Mínima (R\$ milhares) & 630,9 & 288,1 & 732,5 & 380,0 & 871,7 & 300,0 \\
\hline Média (R\$ milhares) & $1.804,1$ & 466,6 & 1960,5 & 911,4 & $2.373,5$ & 613,5 \\
\hline \multicolumn{7}{|l|}{$1 \%$ mais rico } \\
\hline Mínima (R\$ milhares) & 141,2 & 124,2 & 168,7 & 127,0 & 203,1 & 120,0 \\
\hline Média (R\$ milhares) & 403,6 & 203,7 & 464,5 & 263,2 & 552,9 & 214,7 \\
\hline \multicolumn{7}{|l|}{$5 \%$ mais ricos } \\
\hline Mínima (R\$ milhares) & 38,6 & 45,0 & 46,7 & 46,7 & 57,6 & 48,0 \\
\hline Média (R\$ milhares) & 140,3 & 95,9 & 164,6 & 109,8 & 197,7 & 99,7 \\
\hline Média: Brasil (R\$ milhares) & 15,1 & 12,4 & 18,1 & 13,6 & 20,4 & 15,1 \\
\hline
\end{tabular}

Fonte: Renda dos estratos - DIRPF 2006 a 2009; População - IBGE, projeções de população; Renda das famílias - estimada a partir das Contas Nacionais do IBGE; PNAD 2006 a 2012; Censo Demográfico 2010; POF 2008/2009.

Em resumo, em comparação com os dados tributários, os levantamentos domiciliares subestimam tanto a renda média quanto o nível de concentração no topo. No entanto, todas as fontes concordam que, pelo menos no que diz respeito à concentração de renda entre os mais ricos, a tendência de queda da desigualdade no Brasil no período de 2006 a 2012 deixa de ser evidente. Na melhor das hipóteses, pode-se falar em estabilidade, pois o que de fato se observa é um leve aumento. Não há dúvidas de que, à luz de nossos achados a partir de dados tributários, o que sabemos sobre a desigualdade nesse período merece ser avaliado com mais cautela.

\section{CONCLUSÃO}

Neste artigo apresentaram-se as primeiras estimativas para a concentração de renda entre os mais ricos no Brasil calculadas a partir das declarações de Imposto de Renda de Pessoa Física. Calcularam-se, para o período de 2006 a 2012, as frações da renda total apropriadas pelo $0,1 \%$, pelo $1 \%$ e pelos $5 \%$ mais ricos e compararam-se os resultados com os das principais pesquisas domiciliares brasileiras, as PNADs, a POF e os Censos.

A principal conclusão é de que a concentração de renda entre os mais ricos é, de acordo com os dados tributários, substancialmente maior do

DADOS - Revista de Ciências Sociais, Rio de Janeiro, vol. 58, nº 1, 2015 
que a estimada pelos levantamentos domiciliares, sem que tenha havido tendência de queda nos últimos anos. Em média, entre 2006 e 2012, o $1 \%$ mais rico do Brasil se apropriou de pouco menos de $25 \%$ da renda total, sendo que o $0,1 \%$ mais rico, por si só, ficou com $11 \%$. A desigualdade entre os mais ricos também é maior nos dados tributários do que nas pesquisas domiciliares. Nossos dados permitem assegurar que os mais ricos são resistentes à queda da desigualdade que foi observada nos levantamentos domiciliares.

Seja no que diz respeito à desigualdade entre os mais ricos e o resto da população, seja no que se refere à desigualdade entre os mais ricos, as discrepâncias entre os dados tributários e as pesquisas domiciliares tornam-se muito mais agudas a partir do centésimo superior. Nos dois casos, o problema é mais brando para os indivíduos entre os percentis 95 e 99. Não se deve perder de vista que nosso estudo limita-se a identificar rendas apropriadas e declaradas por pessoas físicas. É possível que a desigualdade seja distinta se as rendas declaradas por pessoas jurídicas - que não deixam de ser propriedade de pessoas físicas - sejam também computadas nas medidas de desigualdade. Também é possível que nossa metodologia de interpolação subestime a concentração no topo da distribuição. Em ambos os casos a consequência seria de que nossos cálculos subestimariam a desigualdade real.

(Recebido para publicação em agosto de 2014)

(Reapresentado em dezembro de 2014)

(Aprovado para publicação em fevereiro de 2015) 


\section{REFERÊNCIAS BIBLIOGRÁFICAS}

AFONSO, José Roberto. (2014), IRPF e Desigualdade em Debate no Brasil: O já Revelado e o por Revelar. Tese de Doutorado, Fundação Getulio Vargas, Rio de Janeiro.

ALBUQUERQUE, Paula Medeiros. (1994), Um Estudo da População de Altos Rendimentos no Brasil nos Anos Recentes. Rio de Janeiro, Ipea.

ALVAREDO, Facundo et al. (2013), “The Top 1 Percent in International and Historical Perspective". Journal of Economic Perspectives, vol. 27, no 3, pp. 3-20.

ATKINSON, Anthony B. (2007), "Measuring Top Incomes: Methodological Issues", in A. B. Atkinson e T. Piketty (eds.), Top Incomes over the Twentieth Century: A Contrast between Continental European and English-Speaking Countries. Oxford, Oxford University Press, pp. 18-42.

(2008), “Concentration among the Rich", in J. B. Davies (ed.), Personal Wealth from a Global Perspective. Oxford, Oxford University Press, pp. 64-88.

; PIKETTY, Thomas (eds.). (2010), Top Incomes: A Global Perspective. Oxford, Oxford University Press.

ATKINSON, Anthony B.; PIKETTY, Thomas; SAEZ, Emmanuel. (2011), “Top Incomes in the Long Run of History". Journal of Economic Literature, vol. 49, pp. 3-71.

BARROS, Ricardo Paes de; CURY, Samir; ULYSSEA, Gabriel. (2006), “A Desigualdade de Renda no Brasil Encontra-se Subestimada? Uma Análise Comparativa Usando PNAD, POF e Contas Nacionais", in R. P. de Barros, M. N. Foguel e G. Ulyssea (eds.), Desigualdade de Renda no Brasil: Uma Análise da Queda Recente. Brasília, Ipea.

BOWLEY, Arthur L. (1914), "The British Super-Tax and the Distribution of Income". The Quarterly Journal of Economics, vol. 28, no 2, pp. 255-268.

BRZEZINSKI, Michal. (2014), "Do Wealth Distributions Follow Power Laws? Evidence from 'Rich Lists'”. Physica A: Statistical Mechanics and its Applications, vol. 406, pp. 155-162.

BURKHAUSER, Richard V.et al. (2012), "Recent Trends in Top Income Shares in the United States: Reconciling Estimates from March CPS and IRS Tax Return Data". Review of Economics and Statistics, vol. 94, no 2, pp. 371-388.

CASTRO, Fábio A. (2014), Imposto de Renda da Pessoa Física: Comparações Internacionais, Medidas de Progressividade e Redistribuição. Dissertação de Mestrado, Brasília, Universidade de Brasília.

DIPRETE, Thomas A. (2007), “What Has Sociology to Contribute to the Study of Inequality Trends? A Historical and Comparative Perspective". American Behavioral Scientist, vol. 50, no 5, pp. 603-618.

FEENBERG, Daniel R. e POTERBA, James M. (1993), “Income Inequality and the Incomes of Very High-income Taxpayers: Evidence from Tax Returns", in J. Poterba (ed.), Tax Policy and the Economy (vol. 7). Cambridge, MIT Press, pp. 145-177.

FERREIRA, Marcelo C. (2001), "Permeable, ma non Troppo?: Social Mobility in Elite Sectors, Brazil - 1996". Revista Brasileira de Ciências Sociais, vol. 16, no 47, pp. 141-160.

DADOS - Revista de Ciências Sociais, Rio de Janeiro, vol. 58, n 1, 2015 
Marcelo Medeiros, Pedro H. G. Ferreira de Souza e Fábio Avila de Castro

HOFFMANN, Rodolfo. (1988), "A Subdeclaração dos Rendimentos". São Paulo em Perspectiva, vol. 2, no 1, pp. 50-54.

. (2001), "Income Distribution in Brazil and the Regional and Sectoral Contrasts", in J. J. M. Guilhoto e G. Hewings (eds.), Structure and Structural Change in the Brazilian Economy. Aldershot/Burlington, Ashgate.

(2005), “Distribuição da Renda no Brasil: Mudanças de 2002 para 2003 e a Delimitação dos Relativamente Ricos". Econômica, vol. 7, no 1, pp. 77-95.

HOFFMANN, Rodolfo e NEY, Marlon G. (2008), “A Recente Queda da Desigualdade de Renda no Brasil: Análise de Dados da PNAD, do Censo Demográfico e das Contas Nacionais". Econômica, vol. 10, no 1, pp. 7-39.

KEISTER, Lisa A. (2014), “The One Percent”. Annual Review of Sociology, vol. 40, no 1, pp. 347-367.

e MOLLER, Stephanie. (2000), “Wealth Inequality in the United States". Annual Review of Sociology, vol. 26, no 1, pp. 63-81.

KENWORTHY, Lane. (2007), "Inequality and Sociology". American Behavioral Scientist, vol. 50, no 5, pp. 584-602.

KING, Willford Isbell. (1915), The Wealth and Income of the People of the United States. New York, Macmillan.

KOPCZUK, Wojciech e SAEZ, Emmanuel. (2004), “Top Wealth Shares in the United States, 1916-2000: Evidence from Estate Tax Returns". National Tax Journal, vol. 57, no 2, pp. 445-487.

e SONG, Jae. (2010), “Earnings Inequality and Mobility in the United States: Evidence from Social Security Data Since 1937". The Quarterly Journal of Economics, vol. 125, no 1, pp. 91-128.

LEIGH, Andrew. (2007), "How Closely Do Top Income Shares Track Other Measures of Inequality?". The Economic Journal, vol. 117, no 524, pp. F619-F633.

LLUCH, Constantino. (1982), “Sobre Medições de Renda a partir dos Censos e das Contas Nacionais no Brasil". Pesquisa e Planejamento Econômico, vol. 12, no1, pp. 133-148.

MARX, Karl. (1996), Capital: A Critique of Political Economy. London, Lawrence \& Wishart.

MEDEIROS, Marcelo. (2004), "Estrutura Familiar e Rendimentos do Trabalho dos Ricos". DADOS - Revista de Ciências Sociais, vol. 47, no 2, pp. 365-382.

. (2005a), “O Estudo dos Ricos no Brasil”. Econômica, vol. 7, no 1, pp. 99-128.

. (2005b), O que Faz os Ricos Ricos: O Outro Lado da Desigualdade Brasileira. São Paulo, Hucitec.

MEDEIROS, Marcelo e SOUZA, Pedro H. G. F. de. (2014), “The Rich, the Affluent and the Top Incomes". Current Sociology, pp. 1-26.

MYLES, John. (2003), "Where Have all the Sociologists Gone? Explaining Income Inequality". The Canadian Journal of Sociology, vol. 28, no 4, pp. 551-559.

OHLSSON, Henry; ROINE, Jesper e WALDENSTRÖM, Daniel. (2006), Long-run Changes in the Concentration of Wealth: An Overview of Recent Findings. Helsinki, UNU-WIDER. Disponível em <http:/ /hdl.handle.net/10419/63366>. Acessado em 25/3/2014. 
PARETO, Vilfredo. (1964), Trattato di Sociologia Generale. Milano, Edizioni di Comunità.

PIKETTY, Thomas. (2001), Les Hauts Revenus en France au XXe Siècle. Inégalités et Redistributions 1901-1998. Paris, Grasset.

. (2007), "Top Incomes over the Twentieth Century: A Summary of Main Findings", in A. Atkinson e T. Piketty (eds.), Top Incomes over the Twentieth Century: A Contrast between Continental European and English-Speaking Countries. Oxford, Oxford University Press, pp. 1-17.

(2014), Capital in the Twenty-first Century. Boston, Harvard University Press.

PIKETTY, Thomas e SAEZ, Emmanuel. (2003), "Income Inequality in the United States, 1913-1998". The Quarterly Journal of Economics, vol. 118, no 1, pp. 1-41.

(2006), "The Evolution of Top Incomes: A Historical and International Perspective". American Economic Review, vol. 96, no 2, pp. 200-205.

(2013), “Top Incomes and the Great Recession: Recent Evolutions and Policy Implications". IMF Economic Review, vol. 61, no 3, pp. 456-478.

ROCHA, Sônia. (2002), “A Investigação do Rendimento na PNAD: Comentários e Sugestões à Pesquisa nos Anos 2000”. Texto para Discussão, no 899, Ipea, Rio de Janeiro.

SAEZ, Emmanuel. (2006), "Income and Wealth Concentration in Historical and International Perspective", in A. J. Auerbach; D. Card e J. M. Quigley (eds.), Public Policy and the Income Distribution. New York, Russell Sage Foundation, pp. 221-258.

SOUZA, Pedro H. G. F. (2013), "A Distribuição de Renda nas Pesquisas Domiciliares Brasileiras: Harmonização e Comparação entre Censos, PNADS e POFS”. Brasília, Instituto de Pesquisa Econômica Aplicada (Ipea).

. (2014), Top Incomes in Brazil, 1933-2012: A Research Note. Rochester, NY, Social Science Research Network. Disponível em <http://papers.ssrn.com/abstract= 2537026>. Acessado em 15/12/2014.

TORCHE, Florencia e SPILERMAN, Seymour. (2008), "Household Wealth in Latin America", in J. B. Davies (ed.), Personal Wealth from a Global Perspective. Oxford, Oxford University Press.

USA, COMMISSION ON INDUSTRIAL RELATIONS; WALSH, Francis. P. (1915), Final Report of the Commission on Industrial Relations. Washington, D.C., Barnard \& Miller Print.

VEBLEN, Thorstein. (1988), A Teoria da Classe Ociosa: Um Estudo Econômico das Instituições. São Paulo, Nova Cultural.

VÉLEZ, Juliana L. (2012), Income and Wealth at the Top in Colombia: An Exploration of Tax Records 1993-2010. Paris, Paris School of Economics.

WOLFF, Edward N. (1996), "International Comparisons of Wealth Inequality". Review of Income and Wealth, vol. 42, no 4, pp. 433-451.

DADOS - Revista de Ciências Sociais, Rio de Janeiro, vol. 58, nº 1, 2015 
Marcelo Medeiros, Pedro H. G. Ferreira de Souza e Fábio Avila de Castro

\section{APÊNDICE I}

\section{Interpolação de Pareto}

A interpolação assume que os rendimentos mais elevados seguem uma distribuição de Pareto, cuja função de distribuição acumulada $F(\gamma)$ para a renda $\gamma$, dados os parâmetros $\kappa$ e $\alpha$, pode ser escrita como:

$$
1-F(\gamma)=\left(\frac{\kappa}{\gamma}\right)^{\alpha}, \operatorname{com} \kappa>0 \text { e } \alpha>1
$$

Esses parâmetros podem ser estimados porque a característica principal da distribuição de Pareto é que a razão entre a renda média dos indivíduos com renda maior do que $\gamma$ não depende do valor de $\gamma$, mas apenas do parâmetro $\alpha$ :

$$
\gamma^{*}(\gamma)=\frac{\alpha}{\alpha-1}
$$




\section{APÊNDICE II}

\section{Tabulações Utilizadas nas Interpolações}

Renda Total na DIRPF, segundo Estratos

(2006-2012)

\begin{tabular}{|c|c|c|c|c|}
\hline $\begin{array}{c}\text { Limite Inferior } \\
\text { do Estrato }\end{array}$ & $\begin{array}{c}\text { Limite Superior } \\
\text { do Estrato }\end{array}$ & $\begin{array}{l}\text { Número de } \\
\text { Declarações }\end{array}$ & $\begin{array}{c}\text { Renda Total do } \\
\text { Estrato }\end{array}$ & $\begin{array}{c}\text { Renda Média } \\
\text { do Estrato }\end{array}$ \\
\hline \multicolumn{5}{|l|}{2012} \\
\hline 1.00 & $22,392.00$ & $5,000,114$ & $57,121,228,336$ & 11,424 \\
\hline $22,392.01$ & $37,320.00$ & $7,718,283$ & $222,215,608,273$ & 28,791 \\
\hline $37,320.01$ & $74,640.00$ & $7,166,909$ & $372,566,827,279$ & 51,984 \\
\hline $74,640.01$ & $149,280.00$ & $3,456,902$ & $355,488,532,160$ & 102,834 \\
\hline $149,280.01$ & aberto & $2,275,345$ & $924,840,430,280$ & 406,462 \\
\hline \multicolumn{2}{|r|}{ Total } & $25,617,553$ & $1,932,232,626,328$ & 75,426 \\
\hline \multicolumn{5}{|l|}{2011} \\
\hline 1.00 & $32,700.00$ & $10,391,232$ & $225,970,196,314$ & 21,746 \\
\hline $32,700.01$ & $65,400.00$ & $7,122,599$ & $324,015,022,648$ & 45,491 \\
\hline $65,400.01$ & $130,800.00$ & $3,530,518$ & $317,866,844,982$ & 90,034 \\
\hline $130,800.01$ & aberto & $2,430,025$ & $905,619,879,747$ & 372,679 \\
\hline \multicolumn{2}{|r|}{ Total } & $24,898,481$ & $1,773,713,519,797$ & 71,238 \\
\hline \multicolumn{5}{|c|}{2010} \\
\hline 1.00 & $61,200.00$ & $18,433,467$ & $491,727,627,990$ & 26,676 \\
\hline $61,200.01$ & $91,800.00$ & $2,205,099$ & $163,673,907,890$ & 74,225 \\
\hline $91,800.01$ & $122,400.00$ & $1,085,148$ & $114,028,925,308$ & 105,081 \\
\hline $122,400.01$ & $183,600.00$ & $1,007,232$ & $149,172,283,813$ & 148,101 \\
\hline $183,600.01$ & aberto & $1,232,062$ & $605,400,795,715$ & 491,372 \\
\hline \multicolumn{2}{|r|}{ Total } & $23,963,008$ & $1,524,003,540,716$ & 63,598 \\
\hline \multicolumn{5}{|l|}{2009} \\
\hline 1.00 & $27,900.00$ & $10,823,559$ & $198,714,103,362$ & 18,359 \\
\hline $27,900.01$ & $55,800.00$ & 6429611 & $249,444,868,808$ & 38,796 \\
\hline $55,800.01$ & $111,600.00$ & 3161066 & $243,236,434,871$ & 76,948 \\
\hline $111,600.01$ & aberto & 2168635 & $651,420,071,990$ & 300,383 \\
\hline Total & Total & $24,383,680$ & $1,343,043,317,890$ & 55,080 \\
\hline \multicolumn{5}{|l|}{2008} \\
\hline 1.00 & $24,900.00$ & $11,350,597$ & $182,743,425,729$ & 16,100 \\
\hline $24,900.01$ & $49,800.00$ & $6,494,732$ & $224,710,138,193$ & 34,599 \\
\hline
\end{tabular}

(continua) 
Marcelo Medeiros, Pedro H. G. Ferreira de Souza e Fábio Avila de Castro

Renda Total na DIRPF, segundo Estratos

(2006-2012) (continuação)

\begin{tabular}{|c|c|c|c|c|}
\hline & \multicolumn{3}{|c|}{$(2006-2012)$} & \multirow{2}{*}{$\begin{array}{c}\text { (continuação) } \\
\text { Renda Média } \\
\text { do Estrato }\end{array}$} \\
\hline $\begin{array}{c}\text { Limite Inferior } \\
\text { do Estrato }\end{array}$ & $\begin{array}{c}\text { Limite Superior } \\
\text { do Estrato }\end{array}$ & $\begin{array}{l}\text { Número de } \\
\text { Declarações }\end{array}$ & $\begin{array}{c}\text { Renda Total do } \\
\text { Estrato }\end{array}$ & \\
\hline $49,800.01$ & $99,600.00$ & $3,205,150$ & $220,497,237,418$ & 68,795 \\
\hline $99,600.01$ & aberto & $2,231,728$ & $635,588,848,378$ & 284,797 \\
\hline \multicolumn{2}{|r|}{ Total } & $25,772,762$ & $1,263,810,667,986$ & 49,037 \\
\hline \multicolumn{5}{|l|}{2007} \\
\hline 1.00 & $22,800.00$ & $11,971,162$ & $171,759,540,362$ & 14,348 \\
\hline $22,800.01$ & $45,600.00$ & $5,604,038$ & $177,302,510,275$ & 31,638 \\
\hline $45,600.01$ & $91,200.00$ & $2,655,253$ & $166,266,844,643$ & 62,618 \\
\hline $91,200.01$ & aberto & $1,796,514$ & $469,601,065,761$ & 261,396 \\
\hline \multicolumn{2}{|r|}{ Total } & $25,225,027$ & $985,288,375,440$ & 39,060 \\
\hline \multicolumn{5}{|c|}{2006} \\
\hline 1.00 & $21,000.00$ & $11,096,892$ & $153,032,723,632$ & 13,791 \\
\hline $21,000.01$ & $42,000.00$ & $5,860,856$ & $171,158,683,598$ & 29,204 \\
\hline $42,000.01$ & $84,000.00$ & $2,875,012$ & $166,550,913,195$ & 57,931 \\
\hline $84,000.01$ & aberto & $1,919,637$ & $422,097,063,776$ & 219,884 \\
\hline \multicolumn{2}{|c|}{ Total } & $24,156,253$ & $913,091,475,209$ & 37,799 \\
\hline
\end{tabular}


RESUMO

O Topo da Distribuição de Renda no Brasil: Primeiras Estimativas com Dados Tributários e Comparação com Pesquisas Domiciliares (2006-2012)

Este artigo apresenta a primeira estimativa da concentração de renda entre os mais ricos no Brasil calculada com base nas declarações de Imposto de Renda de Pessoas Físicas para os anos de 2006 a 2012. As principais medidas de desigualdade são as frações da renda total apropriada pelos $0,1 \%, 1 \%$ e $5 \%$ mais ricos. Os resultados são testados e comparados com os das pesquisas domiciliares brasileiras. $\mathrm{O}$ artigo conclui que os dados tributários revelam uma concentração no topo substancialmente maior do que as outras fontes e, em termos gerais, ela permanece estável no período analisado.

Palavras-chave: desigualdade de renda; altos rendimentos; ricos; imposto de renda

\section{ABSTRACT}

The Upper Tip of Income Distribution in Brazil: First Estimates with Income Data and a Comparison with Household Surveys (2006-2012)

This article presents a first estimate of the concentration of income among the richest in Brazil calculated based on income tax return statements between 2006 and 2012. The main inequality measurements are the fractions of the total income appropriated by the $0.1 \%, 1 \%$ and $5 \%$ richest. The results are tested and compared with that of household surveys. The article concludes that income data reveals concentration at the top that is substantially greater than other sources and, in general terms, remained stable in the period analyzed.

Keywords: income inequality; high income; rich; income tax 
Marcelo Medeiros, Pedro H. G. Ferreira de Souza e Fábio Avila de Castro

RÉSUMÉ

Le Sommet de la Pyramide de Répartition des Revenus au Brésil: Premières Estimations à partir de Données Fiscales et Comparaison avec des Enquêtes de Ménage (2006-2012)

Cet article présente les premières estimations de concentration du revenu parmi les personnes les plus riches du Brésil, calculée sur la base des déclarations d'impôt sur le revenu des personnes physiques entre 2006 et 2012. Les principales mesures des inégalités consistent à analyser la part du revenu total que s'approprient les $0,1 \%, 1 \%$ et $5 \%$ les plus riches. Les résultats validés sont comparés avec ceux des enquêtes de ménage brésiliennes. L'article conclut que les données fiscales révèlent une concentration au sommet de la pyramide substantiellement plus élevée que les autres sources, ainsi qu'une relative stabilité durant la période étudiée.

Mots-clés: inégalité de revenu; hauts revenus; riches; impôt sur le revenu

\section{RESUMEN}

La Cumbre de la Pirámide de Distribución de Renta en Brasil: Primeras Estimativas con Datos Tributarios y Comparación con Encuestas de Hogares (2006-2012)

Este artículo presenta la primera estimativa de la concentración de renta entre los más ricos en Brasil calculada a partir de las declaraciones del impuesto de renta de personas físicas entre 2006 y 2012. Las principales medidas de desigualdad son las fracciones de la renta total apropiada por el $0,1 \%, 1 \%$ y $5 \%$ más ricos. Los resultados son testados y comparados con las encuestas de hogares brasileños. El texto concluye que los datos tributarios revelan una concentración en la cumbre de la pirámide significativamente superior que las demás fuentes $\mathrm{y}$, en términos generales, ésta permanece estable en el período analizado.

Palabra clave: desigualdad de renta; altas rentas; ricos; impuesto de renta 